\title{
Editorial: Retaining Quality When Drying Food: Challenges and Solutions
}

\author{
Mohammad U. H. Joardder ${ }^{1 *}$, Azharul Karim ${ }^{2}$ and Sami Ghnimi ${ }^{3,4}$ \\ ${ }^{1}$ Department of Mechanical Engineering, Rajshahi University of Engineering and Technology, Rajshahi, Bangladesh, ${ }^{2}$ Science \\ and Engineering Faculty, Queensland University of Technology, Brisbane, QLD, Australia, ${ }^{3}$ LAGEPP UMR 5007, CNRS, \\ Université Claude Bernard Lyon 1, Villeurbanne, France, ${ }^{4}$ ISARA Lyon, Lyon Cedex, France
}

Keywords: food drying, hybrid-drying, dried food quality, drying kinetic, advanced drying techniques

\section{Editorial on the Research Topic}

\section{Retaining Quality When Drying Food: Challenges and Solutions}

Drying is one of the major processes in the food industry and is a dominant food preservation method. By safely removing moisture from food products, drying reduces microbial growth and nutritional degradation, adds value to the product, reduces transportation and storage costs, increases the shelf life and reduces waste. Although drying is a mature field; many critical research issues still prevail. Drying is a highly energy-intensive lengthy process and results in significant food quality deterioration. Drying is an energy-intensive industrial process that accounts for $\sim 15 \%$ of all industrial energy usage (Chua et al., 2001; Karim and Hawlader, 2005). Improvement in energy efficiency even to some extent in the food drying process will result in sustainable development to global energy. Further research in drying is required to minimize food quality deterioration, drying time, and energy consumption. Fundamental understanding of the drying process, particularly the impact of process conditions and material properties on product quality and energy efficiency is vital in addressing the above-mentioned issues (Pham et al., 2017).

Maintaining high product quality is one of the key issues in the food processing industry. The selection of process parameters and drying method is the determining factor for the quality aspect of dried food (Joardder M. U. et al., 2017). Simultaneous heat and mass transfer during drying cause changes in food structure, modification of important bioactive constituents and changes in the appearance of the product during drying (Joardder M. U. H. et al., 2017). Particularly, most nutrients deteriorate during drying due to their thermolabile characteristics. These changes may also cause significant changes in their bioactivity and bio-accessibility. Moreover, deterioration of textural and aesthetic quality leads to lower acceptance of dried food to the consumers [Joardder et al., 2019, 2015].

Approaches such as application of hybrid drying techniques, optimization of drying conditions, incorporation of appropriate pre-treatment, implementation of nanotechnology and integration of artificial intelligence for real-time quality monitoring and process optimization are the key areas of future research to overcome the current problems of the drying field. In this collection of four papers, researchers and scientists from different fields have come together to address some of the above research issues.

The article by Zartha Sossa et al. critically review the recent literature published in 2019 and 2020 to figure out the feasibility of far-infrared drying techniques and compares the conventional and recently developed advanced drying techniques. Far-infrared drying aims to be one of the most widely used drying techniques in the future due to the benefits it brings such as low energy consumption, higher sensory and rehydration ability, and high nutrient retention. This article identified the most appropriate food items for far-infrared drying and suggests optimum drying 
conditions for preserving the organoleptic characteristics of the product, avoiding damage to thermolabile compounds and obtaining high quality.

Drying kinetics is affected by food sample properties as well as drying conditions. The paper by Zambra et al. investigates the appropriate drying condition for Kageneckia oblonga leaves. The samples were dried under different drying techniques including oven drying (NC), vacuum drying (VNC), convective drying (FC), and microwave-assisted convective drying (MWFC). The authors investigated the energy consumption and quality of the dried $K$. oblonga leaf product during the selected drying methods. The most obvious finding that emerged from this study is that at lower temperatures the dry leaf tends to maintain its original green color although drying time and energy consumptions are higher. The energy consumptions in different drying methods of $K$. oblonga were found to be in the range of $0.20-7.50$ $\mathrm{kW} \cdot \mathrm{h}$. Taking the energy consumption and dried food quality into consideration, the MWFC method is identified as a good option to be used for the large-scale production of dried $K$. oblonga leaves.

Drying is also an important process to develop functional food ingredients from food residues. The review article by Ramírez-Pulido et al. provides an in-depth analysis of the role of different drying methods on the development of functional food ingredients from fruits and vegetable remnants. This review critically discusses the effect of different drying techniques on the quality and characteristics of vegetables and fruit residues powders. This paper points out that vacuum-drying and freezedrying can be exploited by the food industry to integrally valorize these food wastes and produce functional powdered ingredients. Moreover, microwaves or ultrasounds assisted procedures can

\section{REFERENCES}

Chua, K. J., Mujumdar, A. S., Hawlader, M. N. A., Chou, S. K., and Ho, J. C. (2001). Convective drying of agricultural products. Effect of continuous and stepwise change in drying air temperature. Drying Technol. 19, 1949-1960. doi: 10.1081/drt-100107282

Joardder, M. U., Karim, A., Kumar, C., and Brown, R. J. (2015). Porosity: Establishing the Relationship Between Drying Parameters and Dried Food Quality. Cham: Springer.

Joardder, M. U., and Karim, M. (2019). Development of a porosity prediction model based on shrinkage velocity and glass transition temperature. Drying Technol. 37, 1988-2004.

Joardder, M. U., Kumar, C., and Karim, M. (2017). Food structure: its formation and relationships with other properties. Crit. Rev. Food Sci. Nutr. 57, 1190-1205. doi: 10.1080/10408398.2014.971354

Joardder, M. U. H., Masud, M. H., and Karim, M. A. (2017). "Relationship between intermittency of drying, microstructural changes, and food quality," in Intermittent and Nonstationary Drying Technologies (Boca Raton, FL: CRC Press).

Karim, M. A., and Hawlader, M. N. A. (2005). Mathematical modelling and experimental investigation of tropical fruits drying. Int. J. Heat Mass Transfer 48, 4914-4925. doi: 10.1016/j.ijheatmasstransfer.2005. 04.035 be applied to optimize drying rates and improve the powder characteristics. Despite the progress in these advanced drying methods, their implementation is limited due to higher costs and the requirement of specialized staff. This review also highlights the need for pretreatments to increase the drying rates, and enhance the retention of functional properties of the produced food powders.

In the last paper of this issue by Ripoli et al., the magnetic resonance imaging (MRI) technique is used to observe the variation of the water content during drying at four different drying temperatures of $50,60,65$, and $70^{\circ} \mathrm{C}$. The study figures out the optimal pumpkin preservation conditions and establishes the association between variations of the water content and the T2 value. Moreover, it is observed that shrinkage increases with the removal of water at all drying temperatures as the shrinkage stress are directly related to water removal during drying. Eventually, the migration of water is related to the changes in structural and physicochemical properties. This work indicates that observation of the $\mathrm{T}_{2}$ profile is a useful method for determining moisture profiles and associate structural changes on the sample during drying.

Taken the findings of these four articles into consideration, it emerges that, among several alternatives, process optimization is vital in determining appropriate drying conditions, to minimize energy consumption and maximize quality retention.

\section{AUTHOR CONTRIBUTIONS}

MJ: wrote the manuscript in consultation with $\mathrm{AK}$ and SG. All authors contributed to the article and approved the submitted version.

Pham, N. D., Ghnimi, S., Nishani Lakmali Abesinghe, A. M., Joardder, M. U. H., Petley, T., Muller, S., et al. (2017). "Effects of process conditions of intermittent drying on quality of food materials," in Intermittent and Nonstationary Drying Technologies (Boca Raton, FL: CRC Press).

Conflict of Interest: The authors declare that the research was conducted in the absence of any commercial or financial relationships that could be construed as a potential conflict of interest.

Publisher's Note: All claims expressed in this article are solely those of the authors and do not necessarily represent those of their affiliated organizations, or those of the publisher, the editors and the reviewers. Any product that may be evaluated in this article, or claim that may be made by its manufacturer, is not guaranteed or endorsed by the publisher.

Copyright (c) 2021 Joardder, Karim and Ghnimi. This is an open-access article distributed under the terms of the Creative Commons Attribution License (CC BY). The use, distribution or reproduction in other forums is permitted, provided the original author(s) and the copyright owner(s) are credited and that the original publication in this journal is cited, in accordance with accepted academic practice. No use, distribution or reproduction is permitted which does not comply with these terms. 